\title{
EFFECT OF ADDING BANANA PSEUDO STEM (BPS) ON THE MECHANICAL PROPERTIES OF ABS COMPOSITES
}

\author{
Mohamed Sameh Ahmed, Taiser Attia, Ayman Aly Abd El-Wahab, \\ Ramadan El-Gamsy and M. Hazaem Abd El-latif \\ Designs and Production Department, Faculty of Eng., Ain Shams University, Cairo, Egypt.
}

\begin{abstract}
BPS was used as reinforcement fibers in ABS matrix. Banana fibers were pretreated by using Sodium hydroxide solution with $5 \%$ concentration for 24 hours in order to enhance the adhesion interface between banana fibers and ABS Matrix. ABS/BPS composites were prepared at $0,10,20$ and $30 \mathrm{wt} \%$ banana fibers. The ultimate tensile strength (UTS) and impact toughness for BPS/ABS composites at 0,10, 20, $30 \%$ fiber weight percentage were studied. The SEM observation for fracture surfaces was investigated. The thermal stability of the composites is studied using TGA test.
\end{abstract}

\section{KEYWORDS: - BPS/ABS composite, NaOH, UTS, impact toughness, SEM, TGA, thermal stability.}

\section{INTRODUCTION}

Due to environmental pollution aspects and increase of harmful emissions which caused from using non-natural compounds in the industry field and resulted many different health and environmental problems. Natural fibers became good candidates to invade the field of industry as an alternative to synthetic fibers due to low cost, low density and good properties compared with synthetic fibers. [1]. Nowadays, the utilization of AGW are combined between past tradition and present technology through using them as composting, biogas, electricity and animal foods, also they are a big source of natural fibers to be used as filler or reinforce in PMCs [1, 2]. The amount of AGW in Egypt were reached 35 million tons / year (23 million tons of vegetarian wastes and 12 million tons of animal wastes per year), about 21 million tons/year of AGW haven't been utilized till now [3]. The estimated amount of Banana wastes reached 1.7 million tons /year [2]. Banana residues can be used as a source of banana fiber (BF), the production of banana fruit over 130 countries is nearly 120-150 million tons (as the second major production of fruit) with nearly $16 \%$ of total global production of fruit, only $12 \%$ of the weight of banana tree is represented as banana fruit and the others (leaves and pseudo stems, etc.) aren't used as food but used in fiber production $[\mathbf{4 , 5 ]}$. BF can be obtained from many parts of banana plant such as leaves, rachis and stems, many industries such as paper, mats, textiles and composites are improved by BF, many parts of banana tree have application in industry. Pseudo stems considered as a cluster of leaf stalk which aggregated together in cylindrical shape, they have many applications in industry like as cardboards with high quality, ropes for marine field, currency paper and fabric materials, BPS fibers are better than rachis and leaf fibers due to high strength [5, 6], BPS fibers are considered as Bast plant fibers with complex structure of cellulose, hemicellulose and lignin, BPS have high mechanical properties due to high cellulose percentage compared with others[6].

The objective of this paper is to use BPS (extracted from banana tree residues) in form of fibrils with the thermoplastics material as a composite material. ABS is used as a basic matrix and BPS fibers are used as a reinforcing material with different weight percentage of 
(0-10-20-30\%). Mechanical and thermal properties of BPS/ABS composite are investigated in order to be used in various applications. In this study, the parameter is BPS fiber weight percentage (wt \%).

\section{METHODOLOGY}

\section{A. Materials}

Banana Pseudo Stem (BPS) fibers were extracted by banana extractor machine in Qalyubia Governorate - Egypt and supplied by banana kingdom Co. with cellulose percentage of $63-64 \%$ as shown in table 1 and density $750-950 \mathrm{~kg} / \mathrm{m}^{3}$ as shown in table 2

Table 1 Chemical composition of banana BPS fibers $[7,8]$.

\begin{tabular}{|c|c|c|}
\hline Cellulose [\%] & Hemicellulose [\%] & Lignin [\%] \\
\hline $63-64$ & $10-19$ & 5 \\
\hline
\end{tabular}

Table 2 Properties of BPS fibers [9].

\begin{tabular}{|c|c|c|c|}
\hline Density $\left(\mathrm{kg} / \mathrm{m}^{\mathbf{3}}\right)$ & Moisture Content (\%) & Tensile strength (MPa) & Elastic modulus (GPa) \\
\hline $750-950$ & $10-12$ & $180-430$ & 23 \\
\hline
\end{tabular}

ABS granules were supplied from Al-Salam Plastic Co. in Al-Sharabiyah - Cairo with physical properties shown in table 3 .

Table 3 Physical properties of molded ABS [7].

\begin{tabular}{|c|c|c|c|}
\hline Property & Test method & Value of property & units \\
\hline Apparent Density & ASTM D1895 & 250 to 360 & $\mathrm{Kg} / \mathrm{m}^{3}$ \\
\hline Water Absorption @ $23^{\circ} \mathrm{C}, 24 \mathrm{hr}$ & ASTM D570 & 0.2 to 0.31 & $\%$ \\
\hline Tensile Modulus @ $23^{\circ} \mathrm{C}$ & ASTM D638 & 1696 to 2827 & $\mathrm{MPa}$ \\
\hline Tensile Yield Strength @ $23^{\circ} \mathrm{C}$ & ASTM D638 & 34 to 51 & $\mathrm{MPa}$ \\
\hline Notched Izod Impact @ $23^{\circ} \mathrm{C}$ & ASTM D256 & 91 to 411 & $\mathrm{~J} / \mathrm{m}$ \\
\hline
\end{tabular}

\section{B. Pre-treatment of BPS}

The alkaline treatment passes by two basic steps: firstly, the banana pseudo stem fibers (BPS) were treated with $\mathrm{NaOH}$ Solution (5\%) concentration at room temperature for (24 hrs) [10], these fibers were washed by running water for several times to remove $\mathrm{NaOH}$ solution. Secondly, BPS fibers were immersed into $(1 \%)$ hydrochloric acid HCL solution at room temperature $\left(25^{\circ} \mathrm{C}\right)$ for $(10$ minutes $)$ to ensure that these fibers were free from $\mathrm{NaOH}$ solution. These treated fibers were washed by running water for several times to ensure that they were free from HCL solution. They were dried in open air for 24-48 hrs and then, placed in the oven for drying at $80^{\circ} \mathrm{C}$ for $48 \mathrm{Hrs}$.

C. BPS/ABS Composite preparation

ABS was dried in an oven at $80^{\circ} \mathrm{C}$ for 48 hrs. Composites of ABS/ treated BPS with different weight percentage (0-10-20-30\%) were prepared in steps as follows:-

1- BPS fibers were crushed using crushing machine in Al-Salam Plastic Co. 
2- BPS fibers were Sieved through a system of three manual sieves of mesh sizes $(40,60$ and 80$)$ with opening cell dimensions $(0.421,0.28$ and $0.177 \mathrm{~mm})$ respectively. Most of fibers pass the second sieve (60 mesh size) and don't pass the third sieve ( 80 mesh size) which has average size of $0.21 \mathrm{~mm}$ (small size fiber). We study small size fiber as reinforcement in polymeric materials and make all tests on its composites.

3- ABS was placed in a mixer at $180^{\circ} \mathrm{C}$ for $0.25 \mathrm{hrs}$ in mixer machine, and then BPS fiber was added with different mass fraction (0-10-20-30) \% and waited $0.16 \mathrm{hrs}$ to be mixed homogeneously.

4- The \%BPS/ABS mixtures were crushed into small granules by using crushing machine.

5- The small crushed granules were dried in drying machine at $100^{\circ} \mathrm{C}$ for $2 \mathrm{hrs}$.

6- The dried crushed granules were injected using injection molding machine with temperatures $\left(150^{\circ} \mathrm{C} \& 220^{\circ} \mathrm{C}\right)$, pressure equal to $6 \mathrm{MPa}$ and the times of injection and cooling are 10 and 25 seconds respectively.

The photos of BPS fibers at different processing steps (crushing, sieving, treatment and drying) were shown in Fig 1 .

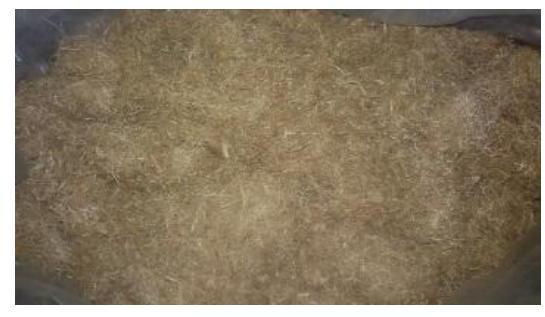

a

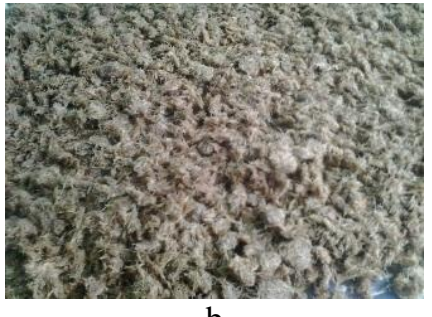

$\mathrm{b}$

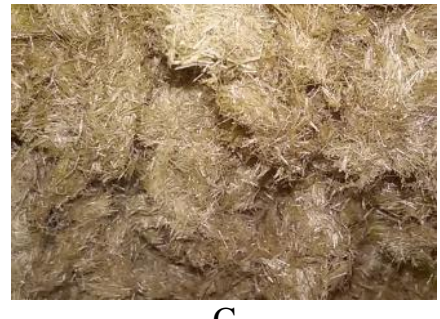

C

Fig 1 banana Pseudo stem fibers

(a) Crushed-Sieved-Untreated. (b) Treated Fiber. (c) Treated - Dried Fiber.

\section{Tensile test}

This test was carried out using universal testing machine with Model: WDW-10 According to ASTM D 638, all samples were put between the flat specimen grips and pulled with speed (2 $\mathrm{mm} / \mathrm{min}$ ) until the failure took place.

\section{E. Impact test}

This test was done according to ISO 179 by using Digital Izord \& charpy impact tester with Model No.: XJJIJ-50A, Impact energy $=0.5-7.5 \mathrm{~J}$ and manufactured at Beijing Jinshengxin Testing Machine Co., Ltd.

F. SEM observation

The microstructure analysis was made using scanning electron microscope (SEM) with (EDX) unit with Model: Quanta 250 FEG (Field Emission Gun); magnification= 140 up to 10000000; Manufactured Co.: FEI company, Netherlands.

\section{G. TGA test}

TGA test was done using Thermo gravimetric device with model (TGA 500). Specimens of $\%$ BPS/ABS composite were heated from $50^{\circ} \mathrm{C}$ to $500^{\circ} \mathrm{C}$ with heating rate of $10^{\circ} \mathrm{C} / \mathrm{min}\left(\mathrm{N}_{2}\right.$ atmosphere). 
EFFECT OF ADDING BANANA PSEUDO STEM (BPS) ON THE MECHANICAL PROPERTIES OF ABS COMPOSITES

\section{RESULTS AND DISCUSSION}

A. Effect of fiber weight percentage in stress strain curve

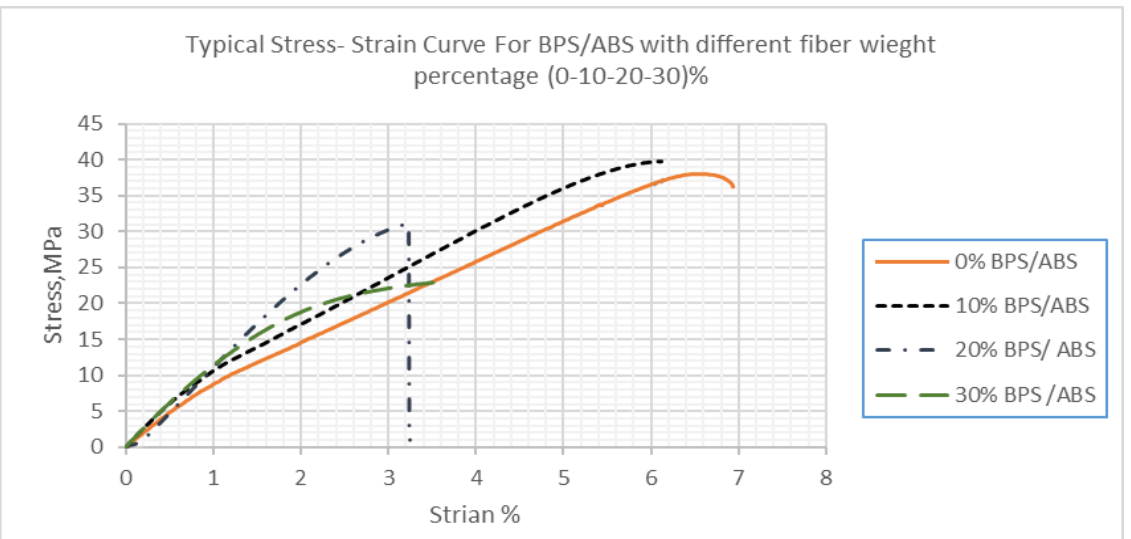

Fig 2 Typical Stress- Strain Curves for BPS/ABS composites with different fiber wieght percentage $(0-10-20-30) \%$

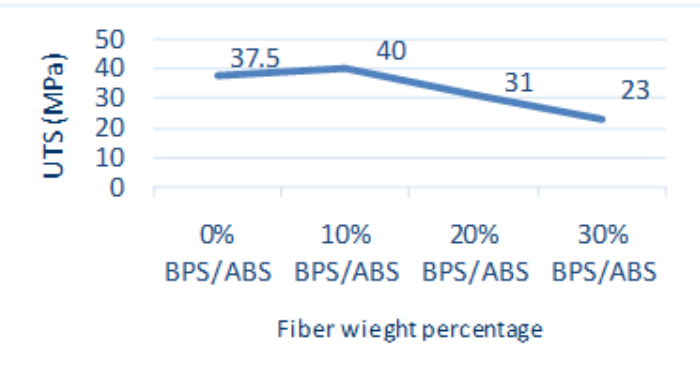

(a)

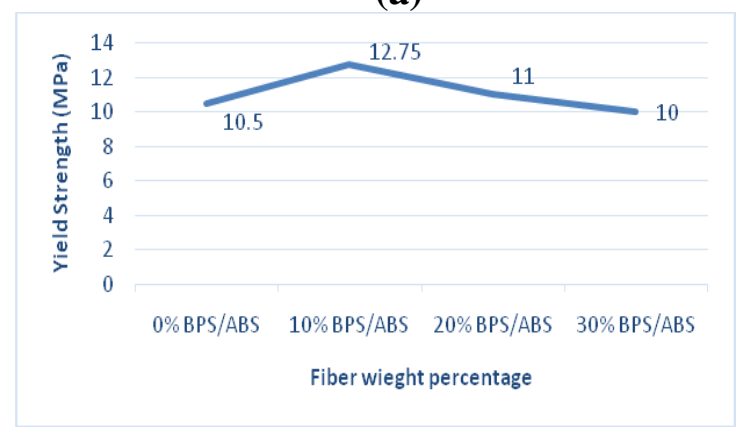

(c)

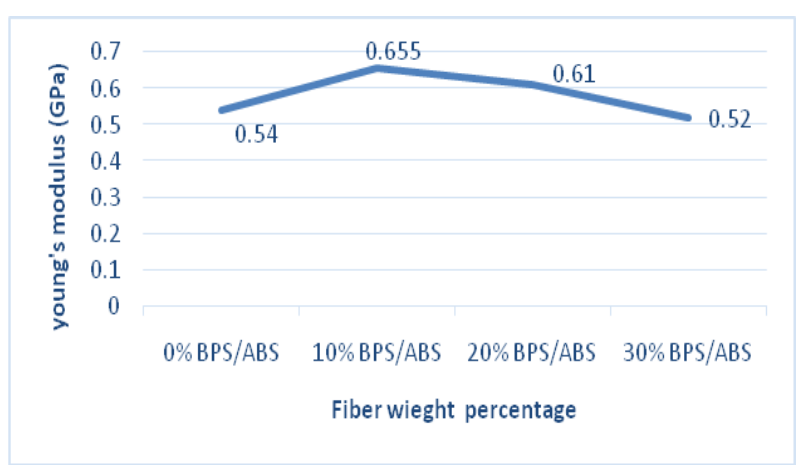

(b)

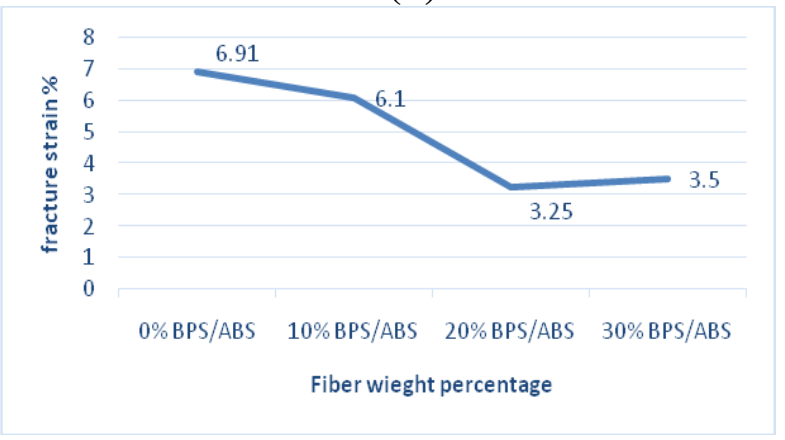

(d)

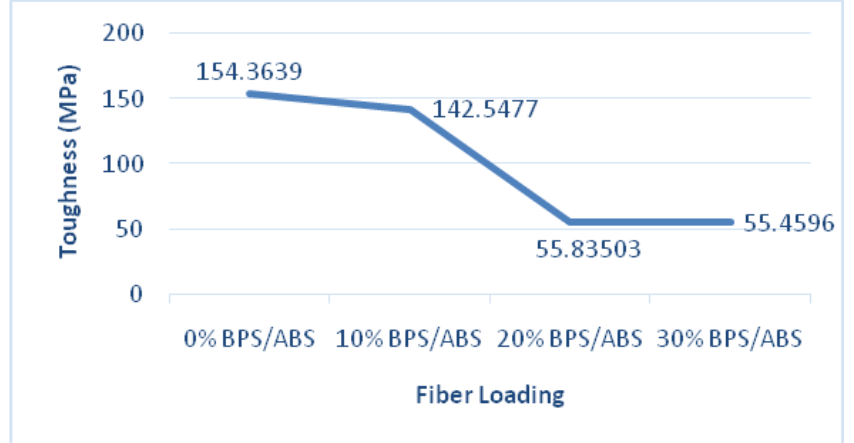

(e)

Fig 3 Mechanical properties obtained from tensile curves for BPS/ABS composite (a) UTS (b) Young's Modulus (c) Yield Strength (d) Fracture strain \% (e) Toughness 
Typical Stress- Strain Curves for BPS/ABS composites with different fiber weight percentage (0-10-20-30\%) were shown in Fig 2 , the ultimate tensile strength UTS increase from 37.5 $\mathrm{MPa}$ at $0 \%$ BPS fiber (pure ABS) to $40 \mathrm{MPa}$ at $10 \%$ BPS fiber, then decrease to 31 and 23 MPa at 20\% and 30\% fiber weight percentage respectively as shown in Fig 3(a), also The young's modulus increase from $0.54 \mathrm{GPa}$ at $0 \%$ BPS fiber to 0.655 at $10 \% \mathrm{BPS}$ fiber and then decrease to 0.61 and $0.52 \mathrm{GPa}$ at $20 \%$ and $30 \%$ BPS fiber weight percentage respectively as shown in Fig 3(b), the yield strength increase from $10.5 \mathrm{MPa}$ at $0 \%$ BPS fiber to 12.75 at $10 \%$ BPS fiber and then decrease to 11 and $10 \mathrm{MPa}$ at $20 \%$ and $30 \%$ BPS fiber weight percentage respectively as shown in Fig 3(c) . The decreasing in UTS, young's modulus and yield strength (above 10\% BPS fiber) were happen due to the dissimilarity between hydrophilic nature of BPS fiber and hydrophobic nature of ABS matrix which led to decreasing in interaction between BPS fiber and ABS matrix, resulting in poor stress transfer between the fibers and polymer matrix $[11,12]$,

The fracture strain \% decrease from $6.91 \%$ at $0 \%$ BPS and reach to $3.5 \%$ at $30 \%$ BPS fiber as shown in Fig 3(d), this is happen due to addition of BPS fiber into ABS (polymeric matrix) which reduce the matrix mobility, thus elongation decrease [12], the toughness decrease from $154.36 \mathrm{MPa}$ at $0 \%$ BPS fiber to $142.45 \mathrm{MPa}$ at $10 \%$ (slight decrease), and then decrease rapidly to $55.8 \mathrm{MPa}, 55.4 \mathrm{MPa}$ at $20 \%$ and $30 \%$ BPS fiber weight percentage respectively as shown in Fig 3(e). The maximum standard deviation of these readings is \pm 0.75 MPa.

The microstructure of BPS/ABS composite with $10 \%$ fiber weight percentage is shown in Fig 4(a), the fibers were distributed uniformly along fracture surface, and approximately no cavities and voids existed, stronger bonding interface between fiber and matrix is played an important role in transferring load and stress through fiber [13]. As fiber weight percentage increased to 20 and $30 \%$ as shown in Fig 4(b, c) (Mag. 150x), the voids appeared and increased, these voids considered as stress concentration where the cracks initiated and propagated through fiber/matrix interface. As the fiber weight percentage in BPS/ABS composite increase, the mechanical properties (such as tensile strength, impact strength and toughness) decrease. Also number of voids increase due to fiber pull out along fracture surface, so the adhesion bonding interface between BPS fiber and ABS matrix become weak to transfer load and stress through it and fibers won't be able to carry load.

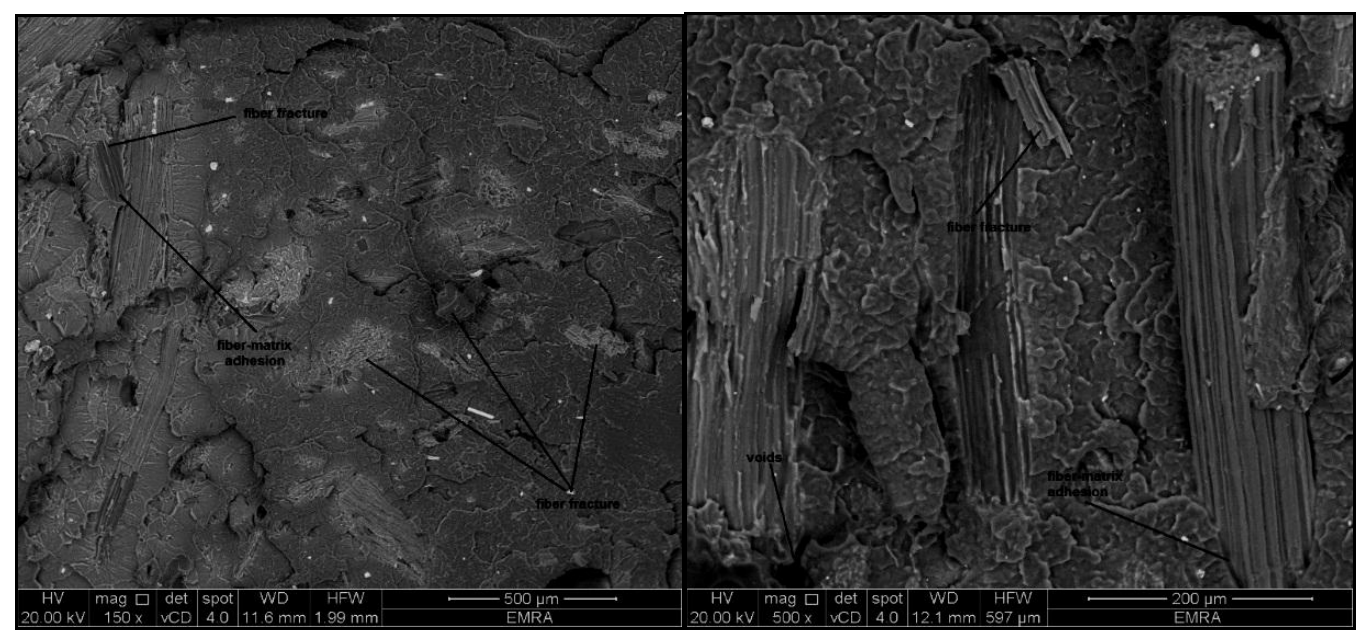

(a) $10 \% \mathrm{BPS} / \mathrm{ABS}$ 


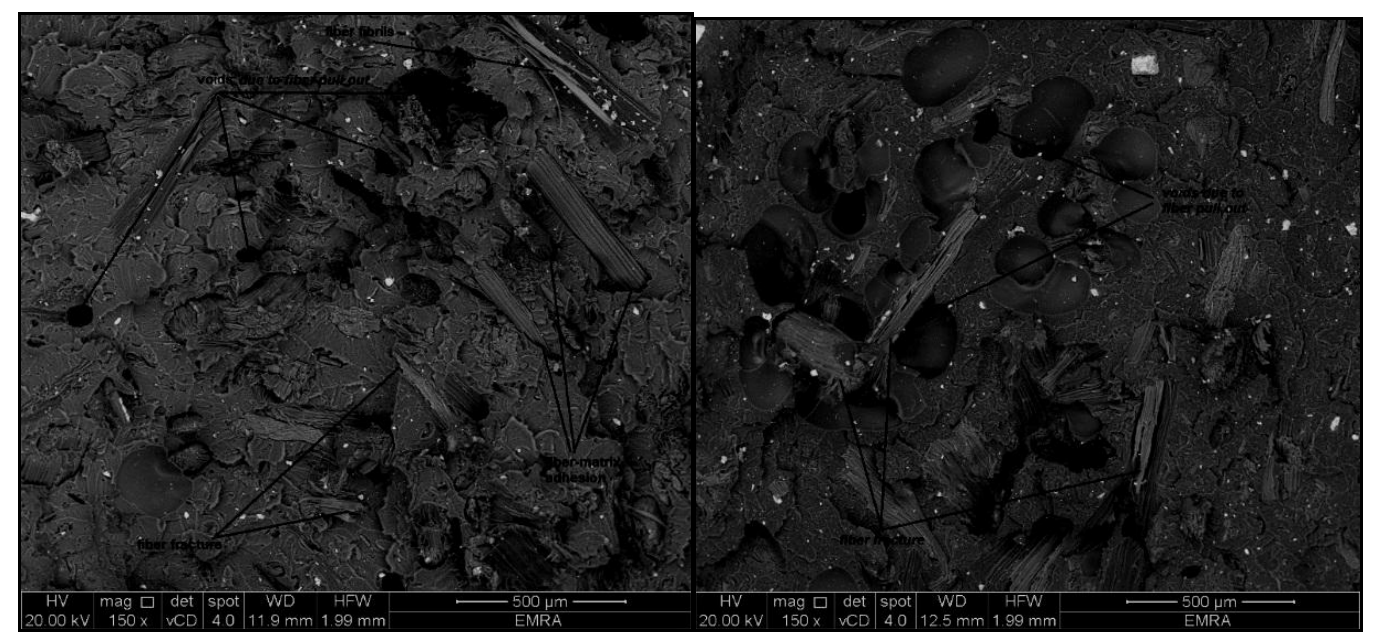

(b) $20 \% \mathrm{BPS} / \mathrm{ABS}$

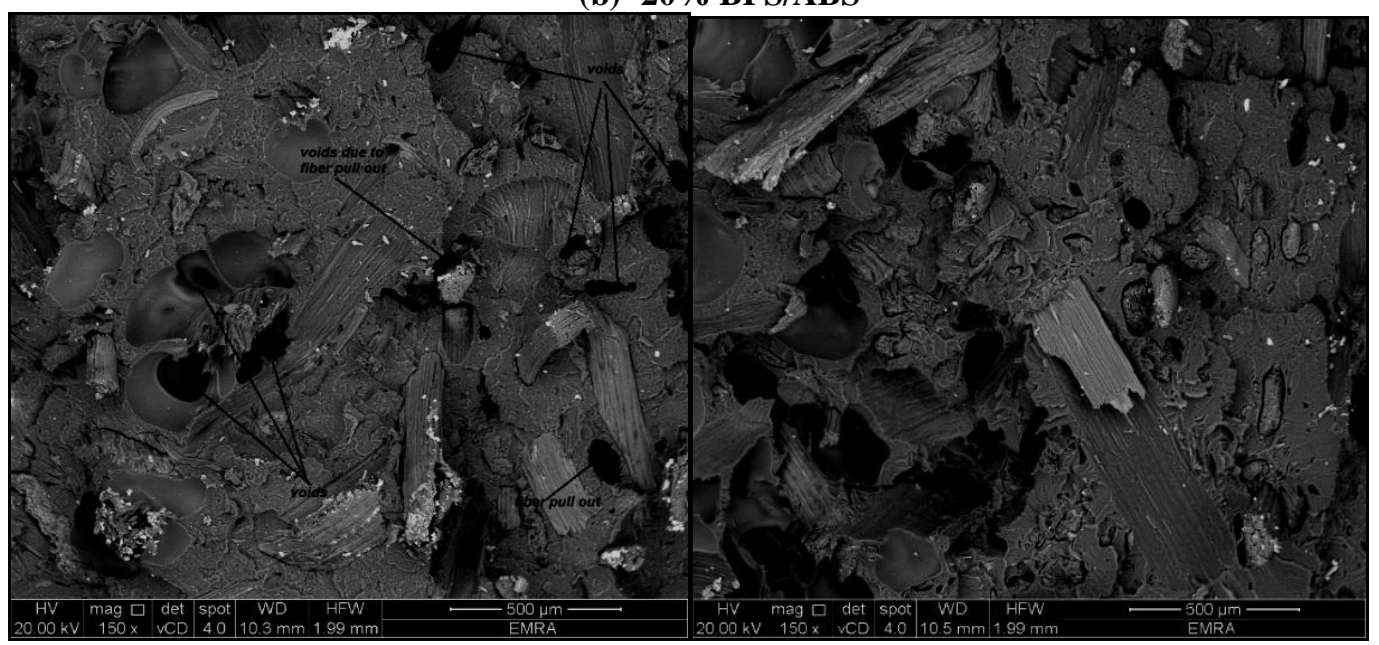

(c) $30 \%$ BPS/ABS

Fig 4 SEM micrographs for BPS/ABS composites at different fiber weight percentage.

B. Effect of fiber weight percentage in impact strength

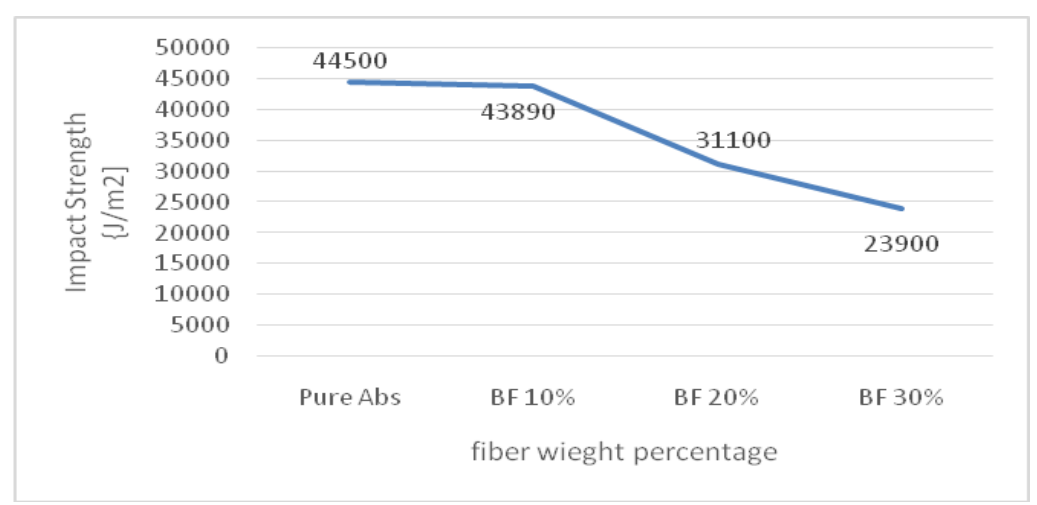

Fig 5 The impact strength diagram at different fiber loading (0-10-20-30\%) 
The impact strengths for \% BPS/ABS composites are shown in Fig 5. It's noticed that the impact strength for BPS/ABS composite decrease with fiber mass fraction increase from $0 \%$ to $30 \%$, this mean that the bonding resistance for BPS/ABS interface decrease, then the composite became more brittle due to decreasing the absorbed energy performed by impact hammer. The maximum standard deviation of these readings is $\pm 950 \mathrm{~J} / \mathrm{m} 2$

\section{Effect of fiber weight percentage on Thermal stability of BPS/ABS composite}

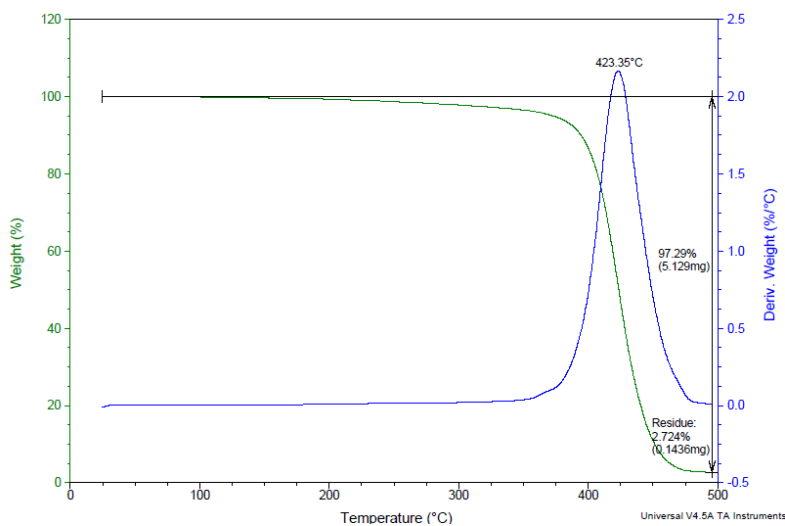

(a) $0 \%$ BPS/ABS.

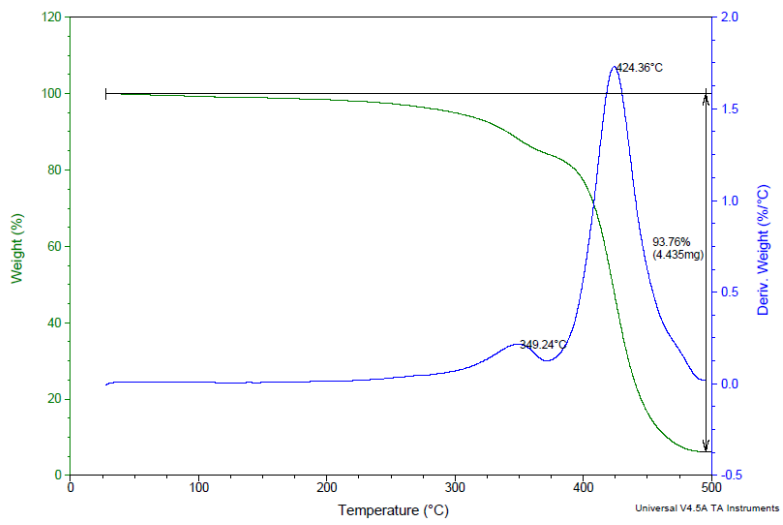

(c) $20 \%$ BPS/ABS.

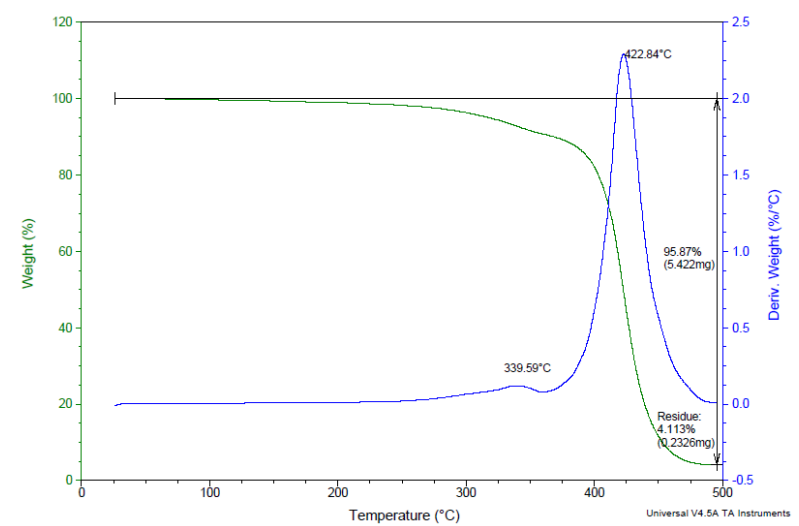

(b) $10 \% \mathrm{BPS} / \mathrm{ABS}$.

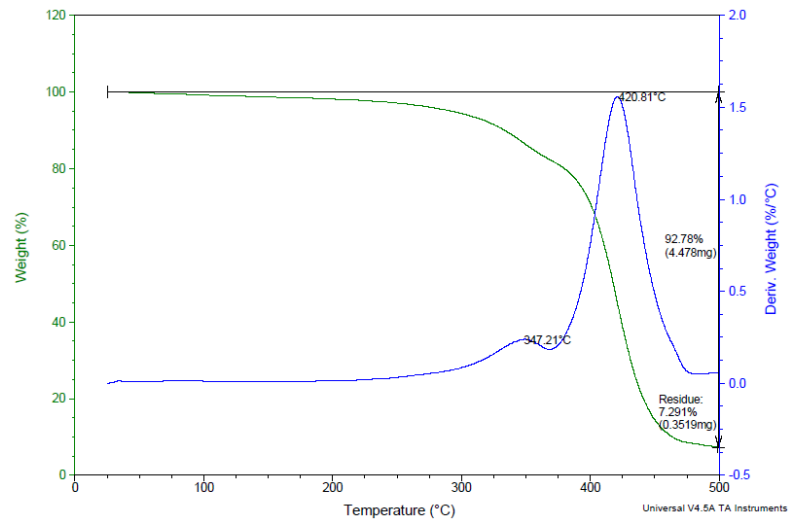

(d) $30 \%$ BPS/ABS.

Fig 6 TGA curves for BPS/ABS composite at different fiber weight percentage.

\begin{tabular}{|c|c|c|c|c|c|}
\hline Sample code & $\begin{array}{c}\text { Sample } \\
\text { size (mg) }\end{array}$ & $\mathbf{T}_{\text {onset }}{ }^{\circ} \mathbf{C}$ & $\mathbf{T}_{\mathrm{f}}{ }^{0} \mathrm{C}$ & $\begin{array}{c}\text { Total Weight } \\
\text { loss \% }\end{array}$ & $\begin{array}{l}\text { Total weight } \\
\text { Residue \% } \\
\text { @ }\left(500^{\circ} \mathrm{C}\right) \\
\end{array}$ \\
\hline $0 \%$ BPS/ABS & 5.272 & 350 & 500 & 97.29 & $2.72 \%$ \\
\hline \multirow{2}{*}{$10 \%$ BPS/ABS } & \multirow{2}{*}{5.656} & 325 & 375 & \multirow{2}{*}{95.9} & \multirow{2}{*}{$4.1 \%$} \\
\hline & & 375 & 490 & & \\
\hline \multirow{2}{*}{$20 \%$ BPS/ABS } & \multirow{2}{*}{4.826} & 330 & 375 & \multirow{2}{*}{92.8} & \multirow{2}{*}{$7.2 \%$} \\
\hline & & 375 & 475 & & \\
\hline \multirow{2}{*}{$30 \%$ BPS/ABS } & \multirow{2}{*}{4.73} & 320 & 370 & \multirow{2}{*}{92.7} & \multirow{2}{*}{$7.29 \%$} \\
\hline & & 370 & 490 & & \\
\hline
\end{tabular}

- $\quad \mathbf{T}_{\text {onset }}=$ temperature at which degradation starts.

- $\mathbf{T}_{\mathbf{f}}=$ final degradation temperature.

Table 4 Degradation temperatures obtained from TGA curves. 
Sample of $0 \%$ BPS/ABS composite was thermally stable up to 350oC, above this temperature, thermal decomposition happens at only one stage till $500 \mathrm{oC}$ with maximum weight loss rate $(2.125 \% / \mathrm{oC})$ at temperature of $423.35 \mathrm{oC}$ and weight residue after run $(2.724 \%$ ) at $500 \mathrm{oC}$ as shown in Fig 6 (a). 10\% BPS/ABS composite sample is shown in Fig 6 (b), it was noticed that thermal degradation occurs at two separated stages; first stage occurred at temperature range (325-375) oC with relative maximum weight loss rate $(0.125 \%$ / oC) at temperature of $339.59 \mathrm{oC}$, second stage occurred at temperature range $(375-490) \mathrm{oC}$ with relative maximum weight loss rate $(2.13 \% / \mathrm{oC})$ at temperature of $422.84 \mathrm{oC}$, the weight residue after run $(4.1 \%)$ at $500 \mathrm{oC}$, Some previous studies revealed that for composite material with $\%$ of natural fibers, the first stage of degradation was occurred due to release of absorbed moisture or vaporization of water from fiber[14].

For 20\%BPS/ABS composite sample, it was noticed that thermal degradation occurs at two separated stages; first stage occurred at temperature range of (330-375) oC with relative maximum weight loss rate $(0.13 \% / \mathrm{oC})$ at temperature of $349.24 \mathrm{oC}$, second stage occurred at temperature range (375-475) oC with relative maximum weight loss rate $(1.75 \% / \mathrm{oC})$ at temperature of $424.36 \mathrm{oC}$, the weight residue after run $(7.2 \%)$ at $500 \mathrm{oC}$ as shown in Fig 6(c).

For $30 \%$ BPS/ABS composite sample, it was noticed that thermal degradation occurs at two separated stages; first stage occurred at temperature range of $(320-370)$ oC with relative maximum weight loss rate $(0.135 \% / \mathrm{oC})$ at temperature of $347.21 \mathrm{oC}$, second stage occurred at temperature range (380-490) oC with relative maximum weight loss rate $(1.55 \% / \mathrm{oC})$ at temperature of $420.81 \mathrm{oC}$ as shown in Fig 6 (d) .The weight residue after run $(7.29 \%)$ at $500 \mathrm{oC}$. The degradation temperatures obtained from TGA are tabulated in Table 4, also the total weight residues \% were graphed in Fig 7

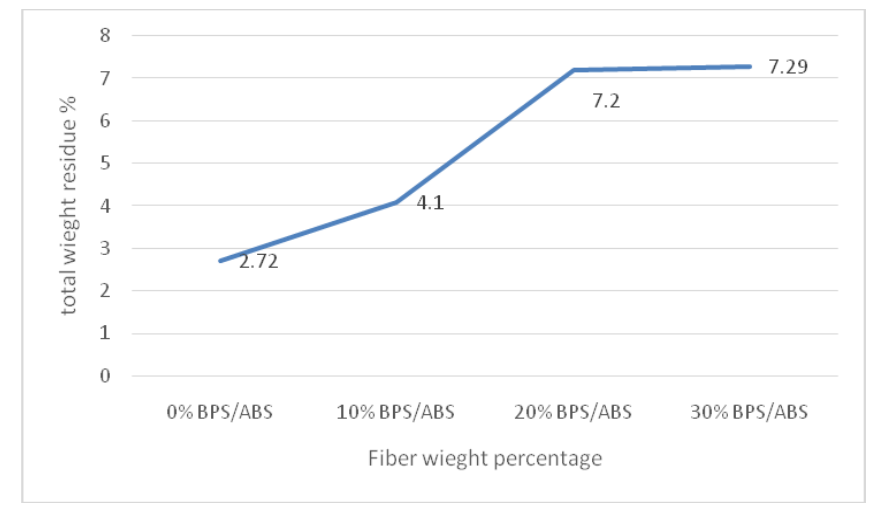

Fig 7 Total weight residue $\% @ 500{ }^{\circ} \mathrm{C}$ at different fiber loading.

The previous studies confirmed that as the total weight residue increase, so the thermal stability increase [14], it can be concluded that with increasing the weight percentage, the total weight residue at $500^{\circ} \mathrm{C}$ increase dramatically from $2.72 \%$ at $0 \%$ BPS to $4.1 \%, 7.2 \%$ and $7.29 \%$ at $10 \%, 20 \%$ and $30 \%$ BPS fiber weight percentage respectively, thus the thermal stability of BPS/ABS composites increase.

CONCLUSIONS

We can conclude all results and analysis in our research in many points:-

1. The ultimate tensile strength UTS of BPS/ABS composite increase as BPS added with $\mathbf{1 0 \%}$ (weight percentage) to ABS pure matrix with an increase of $\mathbf{6 . 7 \%}$ in UTS. Also the yield strength for BPS/ABS composite increase at same weight percentage with an increase of $\mathbf{2 1 . 4 \%}$ in yield strength.

2. $\quad 10 \%$ BPS wt \% is considered as optimum fiber weight percentage which achieves maximum mechanical properties.

3. The thermal stability of BPS/ABS composite increase with addition of BPS fiber in ABS matrix. 


\section{ACKNOWLEGMENT}

Thanks to the Faculty of Engineering (Ain Shams University) and Al-Salam Plastic Company for offering their facilities to complete this experimental work. Also Science and Technology Center of Excellence "STCE" for their support.

\section{REFERENCES}

1- S. D. Abou Hussein and O. M. Sawan," The Utilization of Agricultural Waste as One of the Environmental Issues in Egypt (A Case Study) ", Journal of Applied Sciences Research, Vol 6, no. 8, P 1116-1124, (2010).

2- N. Saba, P. M. Tahir \& M. Jawaid," A review on potentiality of nano filler/natural fiber filled polymer hybrid composites.", Polymers, Vol 6, n 8, P 2247-2273, (2014).

3- H. B. A. Hassan, M. R. el Gebaly, S. S. Abdul Ghani and Y. M. M. Hussein, "An Economic Study of Recycling Agricultural Wastes in Egypt ",Middle East Journal of Agriculture Research, ISSN 2077-4605, Vol 3, no. 3, P 592-608, (2014).

4- N. Reddy, Y. Yang, "Fibers from Banana Pseudo-Stems: Natural Cellulose Fibers from Renewable Resources", Springer-Verlag Berlin Heidelberg, Innovative Biofibers from Renewable Resources, DOI 10.1007/978-3-662-45136-6_7, (2015).

5- D. Mohapatra, S. Mishra, and N. Sutar., "Banana and its by-product utilisation: an overview.”, Journal of Scientific \& Industrial researches, Vol 69, P 323-329, (2010).

6- S. Mukhopadhyay Ph.D., R. Fangueiro Ph.D. , Y. Arpaç and Ü. Şentürk ," banana fiber - variability and fracture behaviour ", Journal of Engineered Fibers and Fabrics , http://www.jeffjournal.org, Vol 3, no. 2, P 592-608, (2008).

7- F. Ahmad, F. Bateni, M. S. Tavana, and A. S. Yahaya. ,"Application of Thermoplastics in Protection of Natural Fibres." ,In Thermoplastic Elastomers. InTech, www.intechopen.com, (2012).

8- J. Sahari, S. M. Sapuan, Y. A. El-shekeil, M. R. Ishak \& R. Akhtar, "Natural fibre-reinforced thermoplastic starch composites", the Royal Society of Chemistry, www.rsc.org, P 109-142, (2016).

9- D. Chandramohan, and K. Marimuthu. ,"A review on natural fibers." International Journal of Research and Reviews in Applied Sciences", Vol 8, n 2, P 194-206, (2011).

10- S. Kalia, B. S. Kaith \& I. Kaur," Pretreatments of natural fibers and their application as reinforcing material in polymer composites - a review", Polymer Engineering \& Science, vol 49, n 7, P 1253-1272, (2009).

11- G. Cristaldi, G. Recca , A. Latteri and G. Cicala, "Composites Based on Natural Fibre Fabrics, Woven Fabric Engineering", Polona Dobnik Dubrovski (Ed.), ISBN: 978-953-307-194-7, InTech,http://www.intechopen.com/books/woven-fabric-engineering/composites-based-onnaturalfibre-fabrics, (2010).

12- N.Prasad, V. K. Agarwal, \& S. Sinha, "Banana fiber reinforced low-density polyethylene composites: effect of chemical treatment and compatibilizer addition", Iranian Polymer Journal, vol 3, no 25, P 229-241, (2016).

13- L. A. Pothan, Z. Oommen, S. Thomas, "Dynamic mechanical analysis of banana fiber reinforced polyester composites. ", Compos Sci Technol, Vol 63, P 283293,www.elsevier.com/locate/compscitech , (2003).

14- J. P. Siregar, M. S. Salit, M. Zaki Ab Rahman, and K. Z. H. M. Dahlan, "Thermogravimetric Analysis (TGA) and Differential Scanning Calometric (DSC) Analysis of Pineapple Leaf Fibre (PALF) Reinforced High Impact Polystyrene (HIPS) Composites.", Pertanika Jour-nal of Science and Technology, Vol 19, no 1,P 161-170, (2011). 